\title{
An Analysis of Sherwood Anderson's Expressionist Art in Winesburg, Ohio
}

\author{
Jiaying Meng ${ }^{1, a}$, Zhifan Wang ${ }^{2, b}$ \\ ${ }^{1}$ Teaching and Research Institute of Foreign Languages, Bohai University, Jinzhou 121013, China; \\ ${ }^{2}$ Harbin Flying Academy, Harbin 150006, China. \\ amengjiaying1@163.com, bwzf402@163.com
}

Keywords: grotesques, expressionist art, alienation, repetition.

\begin{abstract}
Sherwood Anderson is a well-known writer in the history of American literature who has exerted great influence on writers of the flowing generations. As his masterpiece, Winesburg, Ohio reflects many expressionist characteristics. This thesis aims to discuss the expressionist features in the book. Firstly it introduces the development of expressionist art, secondly it analyzes how the expressionist art is revealed in the book from the perspectives of theme, writing techniques and language and plots, finally it summarizes Anderson's expressionist writing and its significance in American literature.
\end{abstract}

\section{Introduction}

Sherwood Anderson is one of the most well-known writers in the history of American modern literature. Many great writers, such as Hemingway, Faulkner, and Steinbeck are deeply influenced by his works. The famous critic Malcolm Cowley referred to him as “writer's writer, the only story teller of his generation who left his mark on the style and vision of the generation that followed."'1] As his masterpiece, Winesburg, Ohio is not merely a story collection but more of an abundant treasure for the mind, leaving endless inspiration for people. The book depicts a picture of a group of grotesques in a small town in the mid-west America during its transition from a rural society to an industrial one. The writer expresses an eager for love and care which had been lost for long in these grotesques and their alienation from others and the world. In the title page of the book, the author wrote: "To the memory of my mother, Emma Smith whose keen observations on the life about her first awoke in me. The hunger to see beneath the surface of lives, this book is dedicated."[2] As is shown, Anderson's creating intention is to observe life beneath the surface, and this view just confirms to the theory of expressionism. Therefore, Anderson's fiction tends to reflect the expressionist art in his writing.

This thesis firstly introduces the development of expressionist art, secondly it discusses how the expressionist art is revealed in the book from the perspectives of theme, writing techniques and language and plots, finally it summarizes Anderson's expressionist writing and its significance in American literature.

\section{Development of the Expressionist Art}

Expressionism, as an important artistic school, prevails in some European countries and America from the beginning of 20th century to 1930s.It comes into being in the field of painting first, and then expands to music, drama, literature, film and so on. Unlike the impressionists who claims to retain the impressions suggested by the outside world, expressionists expect to break the confines of outside world and express their subjective, personal and spontaneous feelings and their inner thoughts. They hold that art is a form of expression, not a representation. Therefore, in the expressionist works, writers aim to reveal what is deeply hidden in the soul; explore profound philosophical meaning, and express the author's subjective feelings such as fear, loneliness, powerlessness and alienation. In expressionist works, the writers tend to dilute the portray of plot and character description, and use 
symbols, exaggeration, distortion and other artistic techniques to reveal the inner world of the characters.

\section{Expressionist Art in the Theme of the Book}

Since human history enters the twentieth Century, science and technology have developed rapidly, and the productivity has also been increased unprecedentedly. However, the growth of material wealth does not bring people a rich spiritual world. The two world wars have destroyed people's faith, resulting in a spiritual wasteland; people who have lost their believes cannot resist the great temptation of material and are more and more subjected to "objects", and they become a dependant of objects gradually. The pursuit of material and the lack of belief have changed the interpersonal relationship: people no longer love and care about each other; rather, they have become mutual exclusive and vigilant. The alienation and estrangement among people is the theme of Expressionist art and such a theme is also reflected in the book, Winesburg, Ohio.

In the first story "hands", the protagonist Wing Biddlebaum has ever been a school teacher in a Pennsylvania town. He considers his caress on his pupil as the way of communication with children. However, this move is misunderstood as a series of homosexual abuse by the parents of his pupils. He is beaten and expelled and finally closes his mind to the outside world and becomes a lonely grotesque; in the story "paper pills", we see another grotesque Doctor Reefy who lives alone in his own world after his wife died cutting off all the connections with other people.

In Winesburg, Ohio, Anderson depicts a group of town people who lives in the America's transition from rural to industrial society. Those who cling to the conventional beliefs can not adjust themselves to the change and have to live in loneliness, frustration and desperation. Being alienated from the harmonious nature and the community by industrialization, they become confused, isolated and incommunicative. In the eye of ordinary people, they are grotesques.

\section{Expressionist Art in the Writing Techniques of the Book}

The intention of expressionism is to explore the inner emotions of people hidden underneath the surface of life and to express more profound life philosophy. Hence in the expressionist works, people become symbols at most of the time. The writer does not aim to depict rich and personalized characters. On the contrary, they often omit detailed descriptions of the characters' appearance. They even utilize the techniques of distortion, exaggeration and symbols to show the deep meanings represented by the characters.

In Winesburg, Ohio, the author often stresses the oddness of these grotesques. In the story "Paper Pills", Doctor Reefy's hands are "extraordinarily large. When the hands were closed they looked like clusters of unpainted wooden balls as large as walnuts fastened together by steel rods."[3]; in the story "mother", Elizabeth is a "tall ghostly figure"; [4]; in the story "the philosopher", Doctor Parcival has strange eyes with the lid of the left eye twitched falling down and snapping up. Those characters appear before the readers like walking phantoms bringing them visual and mental shocks. By portraying the external deformity of these grotesques, the author aims to reveal the sufferings, distortion and loneliness deep in their heart. The strong contradictions between normal and deformed, appearance and inner heart highlight the theme of the work, that is, loneliness and alienation.

Expressionist art tends to be abstract and expressionist works usually have profound symbolic meanings. In Winesburg, Ohio, Anderson employs the technique of repetition to reveal deep significance of the work. Among the repetitive images in the book, the eyes and the hands are the most prominent.

There are two meanings in the repetitive image of the hands. Anderson has deep love for the age of traditional handicraft industry. In his book “The Story Teller's Story”, he expresses his attachment and compliment to the handicraft industry. He claims that the culture is produced from the hands of manual workers who are the father of future generations of artists. The love for the world, for material 
all originated from between their fingers. Therefore, in Winesburg, Ohio, he repeatedly portrays the image of the hands through which he conveys his love and attachment to the era of craft industry.

In the story "hands", Wing Biddlebaun's hands can "pick as high as a hundred and forth quarts of strawberries in a day", and the hands "became his distinguishing feature, the source of his fame"; [5] in the story "Respectability", the telegraph operator Wash Williams was "the ugliest thing in town. His girth was immense, his neck thin, his legs feeble. He was dirty. Everything about him was unclean. Even the whites of his eyes looked soiled". Yet there was something sensitive and shapely in the hand that lay on the table by the instrument in the telegraph office. [6] These hands provide a particularly striking aspect of Anderson's expressionist portraits. They are used to convey beauty and creativity. And besides creating beauty, these hands also should have been used to communicate with people and the world. However, such a communicating function is missing in these grotesques. In the story "hands", Biddlebaun is disgusted and expelled because he has touched his pupils with his hands; in the story "the strength of God", the Reverend Curtis puts his fist through the window of the church because he cannot get rid of his inner lust. These hands lose the function of communication and become symbols of loneliness and desperation of the grotesques.

Eyes, as the windows of the soul, should have been symbols of beauty and purity yet becomes weird in Winesburg, Ohio. The eyes of the Winesburg characters are also described in a way that reveals something twisted and obsessive in their nature. The soiled whites of Wash Williams' eyes reflect his vision of the foulness of women. The tiny bloodshot eyes of the barker, Abner Groff, convey the scope of his narrow existence as he seeks revenge on a neighborhood alley cat. In the description of Dr. Parcival's eyes, Anderson uses an elaborate simile to render vividly something alien and closeted in this figure. There was something strange about his eye, says the narrator: "The lid of the left eye twitched; it fell down and snapped up; it was exactly as though the lid of the eye were a window shade and someone stood inside the doctor's head playing with the cord."[7] Through the image of the eyes, the characters' closed and dim inner world is revealed.

In addition to the repetition of images, some of the background and settings are also symbolic. For example, similar family patterns appear repeatedly in different stories. In Winesburg, Ohio, the family living patterns are usually that boys and young men live alone with poor old women (mother, aunt, grandmother, etc.) in the margins of the town whereas young women often live alone with their fathers, or sometimes their brother. The incomplete family structure symbolizes loneliness and lack of love. Besides, the setting is one of the repeated elements in the stories. [8]In seventeen of the twenty-two stories, the crisis scene takes place in the evening; and the climax usually arrives with the protagonist's momentary epiphany. The repetition of setting gives people a feeling of depression, loneliness, desolation and distortion in the characters' inner world. [9]

\section{Expressionist Art in the Language and Plot of the Book}

Expressionism often exhibits an indifferent and objective attitude with concise, telegraphic language. In Winesburg, Ohio, the language is direct and concise with few compound sentences or ambiguous words and sentences. The author uses shorter and simplified language to make characters' inner world stand out more sharply.

As for the plot of the book, the author holds the same creation idea with expressionist art that advocates non-logical and illusory plots not intrinsically connected.

The plot in Winesburg, Ohio is very simple and there is little development of a story line in terms of cause and effect. Typically a story begins with a physical description of the central character, emphasizing some grotesque feature or trait. Then usually in relation to George Willard as listener, something of the character's past history is revealed (a desertion, a death in the family, an unwanted pregnancy). The story usually ends with the character committing a desperate act (getting drunk, shouting in the streets, striking at the newspaper reporter), then fleeting temporally from the town. [10]By means of distortion and repletion rather than plot, Anderson is able to reveal something about the hidden inner life of his characters an about the nature of society. 


\section{Summary}

As an experimental and innovative writer, Sherwood Anderson employs the expressionist art into his prominent work Winesburg, Ohio. In this book, he portrays a picture of a mid-west small town in America; in this picture, the images of these grotesques are the most impressive touch. They long for love and communication yet are unable to speak out their mind; their inner sufferings and feeling of loneliness and desperation move readers and give the work strength and attraction and cause readers to reflect upon their own living state. As an expressionist work, it had a further significance in American literary history.

\section{References}

[1] Malcolm Cowley: The Introduction to Winesburg, Ohio, Pan Books Ltd., London, 1998, P1.

[2, 3, 4, 5, 6, 7,] Sherwood Anderson: Winesburg, Ohio, Shanghai Foreign Language Education Press, 2004.

[8] Gniadek M. The Art of Becoming: Sherwood Anderson, Frank Sargeson and the Grotesque Aesthetic[J]. Journal of New Zealand Literature, 2005, pp21-35. [4] R.J. Ong, J.T. Dawley and P.G. Clem: submitted to Journal of Materials Research (2003) .

[9, 10] John W. Crowley: New Essays on Winesburg, Ohio, Cambridge University Press, London, 1990, pp. 27-49. 